\title{
Thin-Layer Spectroelectrochemical Cell with Optical Fibers for Low-Temperature Measurements
}

\author{
Akio ICHIMURA*, Jiro NAKA and Toyokichi KITAGAWA \\ Received January 12, 1994 ; Accepted March 10, 1994
}

\begin{abstract}
A versatile thin-layer spectroelectrochemical cell, in which the thin-layer channel is easily constructed by holding a platinum mesh between two fiber optical guides, is described. The thin-layer cyclic voltammetry, chronocoulometry, and spectroelectrochemistry are conducted in the temperature range of -50 to $50{ }^{\circ} \mathrm{C}$. The solution resistance is $100 \Omega$ and the time required for complete electrolysis is $30 \mathrm{~s}$ in acetonitrile containing $0.5 \mathrm{~mol} / \mathrm{dm}^{3}$ tetrabutylammonium hexafluorophosphate. The usefulness of spectroelectrochemical measurements at a low temperature using this cell is demonstrated by obtaining the visible absorption spectrum of an electrogenerated dinuclear palladium(II) complex in N,N-dimethylformamide.
\end{abstract}

\section{INTRODUCTION}

The combination of electrochemistry and spectroscopy provides a very useful method for the redox and spectral characterization of inorganic, organic, and biological compounds ${ }^{1)}$. Spectroelectrochemical techniques with an optically transparent thin-layer electrode (OTTLE) cell have been widely used for in-situ UV-visible spectral observation of electrochemical generated species. Since the report of the OTTLE with a metal minigrid as a working electrode ${ }^{2)}$, there has been much improvement of designs of optically transparent electrode cell ${ }^{1)}$. However, the delicate construction of the cell and the tedious operations such as the filling of deaerated sample solution limit the use of these techniques for investigators who are interested in redox chemistry.

Department of Chemistry, Faculty of Science, Osaka City University (3-3-138 Sugimoto, Sumiyoshi-ku, Osaka 558, Japan)

Key Words: Spectroelectrochemistry, LowTemperature Measurements, Nonaqueous Solution, Palladium Complex
This report describes the design and characterization of a new OTTLE cell in which two optical fibers serve as the thin-layer walls and the optical guides. This cell, with a jacket for the maintenance of a desired temperature, allows the spectroelectrochemical measurements in the temperature range of -50 to $50^{\circ} \mathrm{C}$. Especially the UV-visible absorption measurements below the freezing point of water are free from dew condensation of moisture, which develops on outer surfaces of optical windows and interferes with the spectral measurements at a conventional OTTLE cell ${ }^{3)}$. The usefulness of the low-temperature measurements is demonstrated by obtaining the spectrum of an electrogenerated palladium complex with an unusual oxidation state which is unstable at room temperature.

\section{EXPERIMENTAL}

\subsection{Spectroelectrochemical cell con- struction}

An illustration of the OTTLE cell is shown in Fig. 1. The thin-layer electrode is con- 
structed by holding a $9 \mathrm{~mm}$ diameter piece of platinum minigrid (Nippon Denkyu Kogyo, Inc., 100 mesh) between two optical fibers (Sumita Optics Glass Manufacturer, LGCD20500 ) in the solution bulk. The fibers serve as guides of incident and transmitted lights, respectively and are covered with $9 \mathrm{~mm}$ outer diameter Teflon tubes. The electrode diameter is large enough with respect to the $2 \mathrm{~mm}$ diameter of the fiber edge to prevent the optical beam from passing through the edge or outside of the minigrid. Teflon spacers $(9 \mathrm{~mm}$ diameter, $0.08 \mathrm{~mm}$ thickness) are used for providing the thin-layer channel and insulating the working electrode from a metal sheath with which the fibers are covered at both ends. The two light guide parts are connected along with the spacers and the platinum minigrid with a heatshrinkable Teflon tube, which has four $1 \times 5$ $\mathrm{mm}$ holes at the upper, lower, front, and back sides along the channel to provide the electrolyte conducting and to exchange the sample solution in the thin-layer channel with the bulk solution. A platinum mesh counter electrode is twisted around the one of the $9 \mathrm{~mm}$ diameter Teflon tubes. The leads of $0.1 \mathrm{~mm}$ platinum wire are connected by press-attaching to the working and counter electrodes, respectively. The lead wire for the working electrode is covered with a heat-shrinkable Teflon tube to prevent electrolysis on the platinum of the leads.

The construction of the glass vessel part with the jacket of the OTTLE cell was previously presented. ${ }^{4)}$ Teflon thermometer adapters with an O-ring (NRK T 15) are used to hold the fiber optical guides. One end of the salt bridge tube is positioned close to the working electrode to reduce the IR potential drop.

\subsection{Reagent}

$\left[\mathrm{Pd}_{2}(\mathrm{mpyt})_{4}\right]$, where mpyt is 4-methylpyridine-2-thiolate, was prepared by a previous literature procedure ${ }^{5)}$. Tetrabutylammonium hexafluorophosphate $\left(\mathrm{Bu}_{4} \mathrm{NPF}_{6}\right)$ was prepared
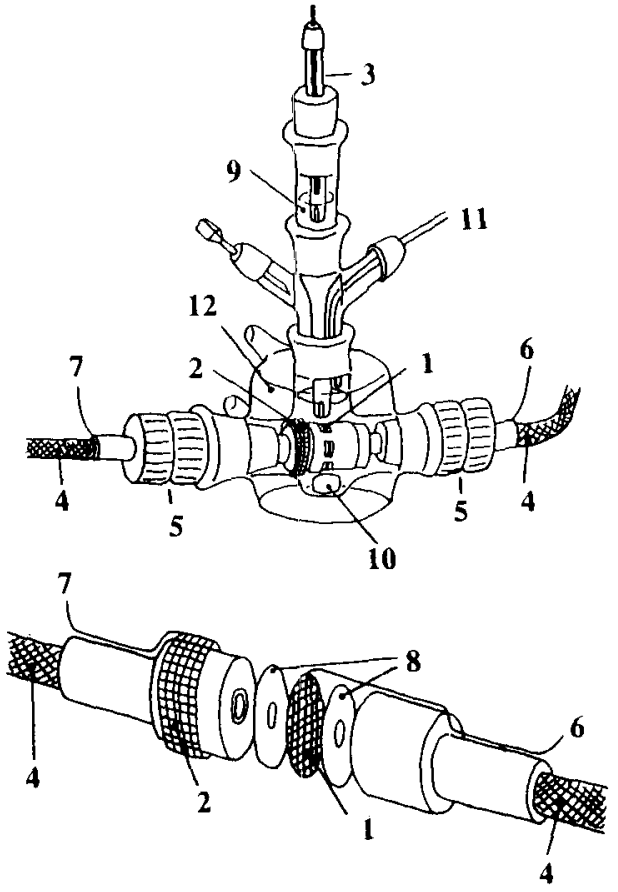

Fig. 1 Schematic illustration of the OTTLE cell (top) and the thin-layer part (bottom). (1) platinum minigrid working electrode; (2) platinum mesh counter electrode; (3) reference electrode; (4) fiber optical guide; (5) holder; (6) lead for working electrode; (7) lead for counter electrode; (8) Teflon spacer; (9) salt bridge; (10) stirring bar; (11) inlet for sample solution or inert gas; (12) jacket.

by metathesis of aqueous potassium hexafluorophosphate and tetrabutylammonium bromide solutions, recrystallized three times from ethanol, and dried at $70^{\circ} \mathrm{C}$ in vacuo. Tetrabutylammonium chloride $\left(\mathrm{Bu}_{4} \mathrm{NCl}\right)$ was purified by a conventional manner. Acetonitrile was dried over molecular sieves $4 \mathrm{~A}$, purified by fractional distillation under a nitrogen atmosphere. N,N-Dimethylformamide (DMF) was dried over molecular sieves $4 \mathrm{~A}$ and anhydrous copper sulfate to remove water and amines and fractionally distilled under reduced pressure. 
Purified solvents were stored under argon in the dark. All other reagents were of reagent grade and were used without further purification.

\subsection{Apparatus}

Electrochemical experiments were performed with a Nichia potentiostat NR-IR 1000 coupled to a Huso potential sweeper unit HECS-321B, a Huso coulometer HECS-434B, and a Graphtech $x-y$ recorder WVX-2400. All potentials were measured with respect to an $\mathrm{Ag} / 0.01 \mathrm{~mol} / \mathrm{dm}^{3} \mathrm{AgPF}_{6}+0.1 \mathrm{~mol} / \mathrm{dm}^{3}$ $\mathrm{Bu}_{4} \mathrm{NPF}_{6}$ (acetonitrile) reference electrode. A Shimadzu spectrophotometer UV-2100S was used for UV-visible absorption measurements. The temperature of the spectroelectrochemical cell was maintained by circulating a mixture of water and ethylene glycol through the jacket. The fluid temperature was controlled within +0.1 ${ }^{\circ} \mathrm{C}$ with a Neslab constant temperature circulator RTE-110.

\subsection{Procedure}

All solutions and the OTTLE cell are purged with argon prior to the electrochemical and spectroelectrochemical measurements. Deoxygenated solutions are transferred into the cell by positive pressure of argon. Alternatively, known amounts of solid samples, which may be unstable in solution at ambient temperature, can be put into the base electrolyte solution and dissolved with aid of stirring. The base electrolyte solution has been deoxygenated and maintained at a desired temperature. The solution volume necessary for the measurements is $5 \mathrm{~cm}^{3}$. The argon gas continues to flow over the surface of the bulk solution during the experiment. After each thinlayer electrochemical or spectroelectrochemical measurement, the gas can be bubbled for 1 min through the solution stirred by a magnetic stirrer to exchange completely the solution in the thin-layer channel with the bulk solution.

\section{RESULTS AND DISCUSSION}

\subsection{Geometric reproducibility of the thin-layer cell}

The optical path length and the solution volume of the OTTLE cell were calibrated each time the cell was constructed. The average path length was found to be $0.372+0.004$ mm $(n=5)$ by absorbance measurements of $2.00 \mathrm{mmol} / \mathrm{dm}^{3}$ tris(bipyridine)iron(II) aqueous solution using the molar absorptivity of $8520 \mathrm{dm}^{3} /(\mathrm{mol} \mathrm{cm})$ at $\left.521 \mathrm{~nm}^{7}\right)$. The average volume was determined to be $11.4+0.4 \mu \mathrm{L}$ ( $\mathrm{n}$ = 5) by thin-layer coulometry of $1.00 \mathrm{mmol} /$ $\mathrm{dm}^{3}$ ferrocene in acetonitrile containing 0.5 $\mathrm{mol} / \mathrm{dm}^{3} \mathrm{Bu}_{4} \mathrm{NPF}_{6}$ using the equation of $V=(n$ $F C$ ), where $V$ is the solution volume of thinlayer, $Q$ the charge passed by electrolysis, $n$ the number of electrons, $C$ the sample concentration, and $F$ the Faraday constant. These results of calibration support the good reproducibility of cell geometry on the repeated construction. This permits the quantitative spectroscopic measurements as well as the coulometric determination of the number of electrons transferred in an electrochemical reaction.

Furthermore, the easy exchange of the thinlayer solution with the bulk solution by stirring allows the successive electrochemical measurements such as thin-layer cyclic voltammetry, chronocoulometry, and spectroelectrochemistry without reconstruction of the cell.

\subsection{Electrochemical characterization of the OTTLE cell}

Figure 2 shows a typical thin-layer cyclic voltammogram for the oxidation of $1.2 \mathrm{mmol} /$ $\mathrm{dm}^{3}$ ferrocene in $0.5 \mathrm{~mol} / \mathrm{dm}^{3} \mathrm{Bu}_{4} \mathrm{NPF}_{6}$ - acetonitrile. Almost symmetric current-potential curves with the peak separation of $25 \mathrm{mV}$ are obtained with a scan rate of $2 \mathrm{mV} / \mathrm{s}$ at $25^{\circ} \mathrm{C}$. This value of peak separation is much smaller 


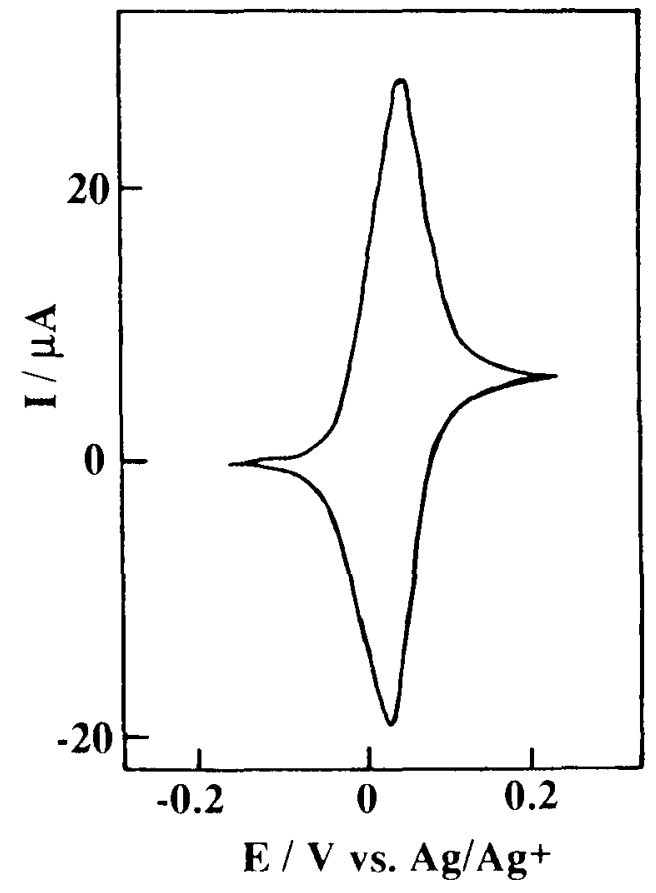

Fig. 2. Thin-layer cyclic voltammogram of 1.2 $\mathrm{mmol} / \mathrm{dm}^{3}$ ferrocene in $0.5 \mathrm{~mol} / \mathrm{dm}^{3} \mathrm{Bu}_{4} \mathrm{NPF}_{6}$ acetonitrile at $25{ }^{\circ} \mathrm{C}$ with a scan rate of 2 $\mathrm{mV} / \mathrm{s}$.

than that of $200 \mathrm{mV}$ obtained under the same conditions at a conventional OTTLE cell ${ }^{3)}$ but larger than the theoretical value of $0 \mathrm{mV}$ for a reversible reaction under thin-layer voltammetric conditions ${ }^{8)}$ where the concentrations of soluble reactant and product can be considered uniform within the thin-layer cell. The difference in peak separation between two thin-layer cells is explained in terms of the IR potential drop. The uncompensated solution resistance in the present cell is $100 \Omega$, which is about one-tenth of that in the conventional cell. In addition, the voltammetric peak currents, proportional to the solution volume of thin-layer, for the present cell are smaller than those for the conventional cell. The small but significant peak separation of $25 \mathrm{mV}$ is not due to the IR drop ( $30 \mu \mathrm{A} \times 100 \Omega=3 \mathrm{mV})$ but

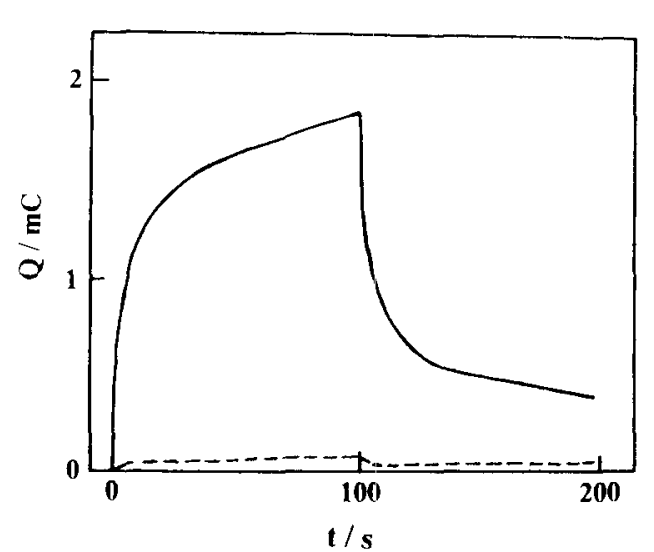

Fig. 3 Double potential step thin-layer chronocoulogram of $1.2 \mathrm{mmol} / \mathrm{dm}^{3}$ ferrocene in $0.5 \mathrm{~mol} / \mathrm{dm}^{3} \mathrm{Bu}_{4} \mathrm{NPF}_{6}$ - acetonitrile at $25^{\circ} \mathrm{C}$. Forward potential step is from -0.3 to $+0.4 \mathrm{~V}$ and the backward is opposite.

probably due to the deviation at a scan rate of $2 \mathrm{mV} / \mathrm{s}$ from the ideal thin-layer voltammetric conditions $^{8)}$.

Figure 3 shows the corresponding thinlayer chronocoulometric curve under double potential step conditions. Upon application of an enough positive potential to oxidize ferrocene, the amount of charge passed increases rapidly for the first $15 \mathrm{~s}$. The time required for complete electrolysis within the thin-layer cell is $30 \mathrm{~s}$. The re-reduction process shows essentially the same features. The charges consumed for complete electrolysis in forward and backward processes are in agreement with each other.

\subsection{Spectroelectrochemical characteri- zation}

Electrochemical characterization for the oxidation of $\left[\mathrm{Pd}_{2}(\mathrm{pyt})_{4}\right]$, where pyt is pyridine2-thiolate), has been accomplished by conventional cyclic voltammetry and bulk electrolysis coulometry in dichloromethane ${ }^{5)}$. In the presence of chloride ion, the two-electron oxida- 


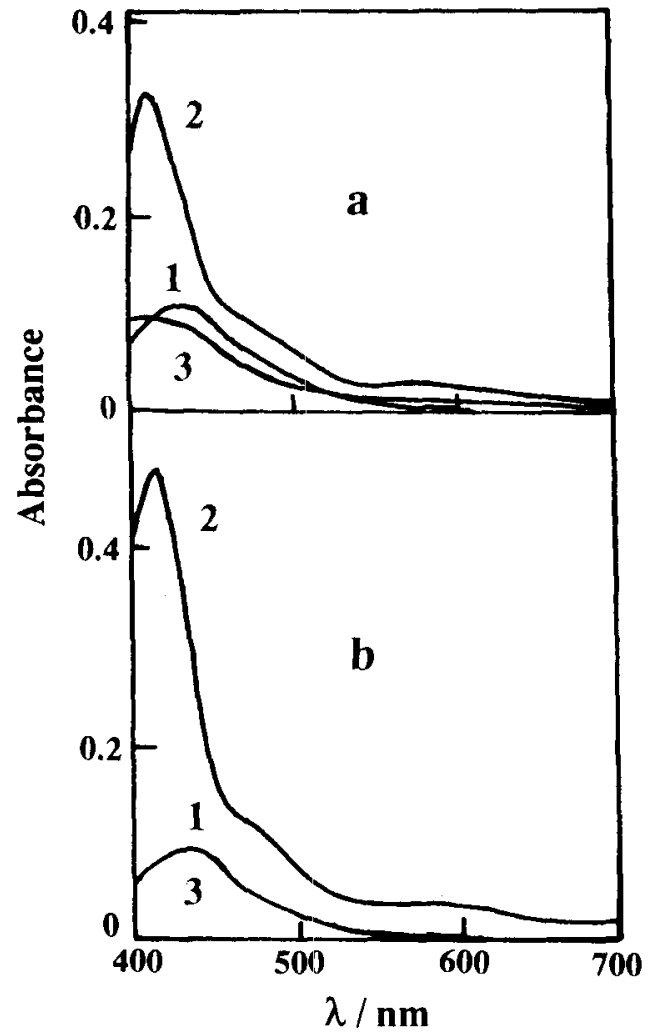

Fig. 4 Visible spectra of $1.0 \mathrm{mmol} / \mathrm{dm}^{3}$ $\left[\mathrm{Pd}_{2}(\mathrm{mpyt})_{4}\right]$ in $0.01 \mathrm{~mol} / \mathrm{dm}^{3} \mathrm{Bu}_{4} \mathrm{NCl}+0.5$ $\mathrm{mol} / \mathrm{dm}^{3} \mathrm{Bu}_{4} \mathrm{NPF}_{6}-\mathrm{DMF}$ on potential application of (1) $-0.4,(2)+0.3$ and (3) $-0.4 \mathrm{~V}$ at (a) 25 and (b) $-10^{\circ} \mathrm{C}$.

tion product was assigned to be $\left[\mathrm{Pd}_{2} \mathrm{Cl}_{2}(\mathrm{pyt})_{4}\right]$ with unusual oxidation states of palladium(III). The dinuclear palladium(III) complex, however, is too unstable in solution at room temperature to be isolated as a solid. Thus, the spectroelectrochemical measurements of the methyl derivative, $\left[\mathrm{Pd}_{2}(\mathrm{mpyt})_{4}\right]$, which is more soluble in organic solvents were conducted in DMF containing $0.01 \mathrm{~mol} / \mathrm{dm}^{3}$ $\mathrm{Bu}_{4} \mathrm{NCl}$ and $0.05 \mathrm{~mol} / \mathrm{dm}^{3} \mathrm{Bu}_{4} \mathrm{NPF}_{6}$ to characterize spectroelectrochemically $\left[\mathrm{Pd}_{2}^{\mathrm{II}}{ }_{2}\right]$ species. In thin-layer cyclic voltammograms a relatively small re-reduction peak with respect to the oxidation peak is shown at $25^{\circ} \mathrm{C}$, whereas almost symmetric peaks, corresponding to $\left[\mathrm{Pd}_{2}(\mathrm{mpyt})_{4}\right]+2 \mathrm{Cl}^{-}=\left[\mathrm{Pd}_{2} \mathrm{Cl}_{2}(\mathrm{mpyt})_{4}\right]+2 \mathrm{e}^{-}$ are observed around $\mathrm{O} \mathrm{V}$ at $-10^{\circ} \mathrm{C}$. Figure 4-a and $-b$ show the spectra before and after potential applications for $60 \mathrm{~s}$ at 25 and $-10^{\circ} \mathrm{C}$, respectively. The spectrum of the re-reduced solution (Fig. 4-a 3 ) is not identical with that of the original solution. This means that the curve drawn by 2 in Fig. 4-a does not represent the correct spectrum of $\left[\mathrm{Pd}_{2} \mathrm{Cl}_{2}(\mathrm{mpyt})_{4}\right]$. On the other hand, the reversible interconversion without any decomposition between two oxidation states of $\left[\mathrm{Pd}_{2}^{\mathrm{II}}\right]$ and $\left[\mathrm{Pd}^{\mathrm{II}}{ }_{2}\right]$ is observed at $-10^{\circ} \mathrm{C}$, and the spectrum of the $\left[\mathrm{Pd}_{2}^{\mathrm{III}}\right]$ species can be reported for the first time.

The spectroelectrochemical measurements at low temperature using the OTTLE cell reported here are very useful to characterize mono- and multi-nuclear complexes with unusual oxidation state(s) and/or a mixed valence state, which may be unstable at ambient temperature and can not be isolated, and to study chemical kinetics associated with the electrochemical reaction.

\section{REFERENCES}

1) W. R. Heineman, F. M. Hawkridge and H. N. Blount, Electroanalytical Chemistry Vol. 13, A. J. Bard, ed., Dekker, New York, pp. 1-104 (1983).

2) R. W. Murray, W. R. Heineman and G. W. O'Dom, Anal. Chem., 39, 1666 (1967).

3) A. Ichimura, W. R. Heineman and E. Deutsch, Inorg. Chem., 24, 2134 (1985).

4) A. Ichimura and H.Tsuzuki, Fabrica (Repot of Central Workshop of Osaka City University), No. 4, p. 54 (1992).

5) K. Umakoshi, A. Ichimura, I. Kinoshita and S. Ooi, Inorg. Chem., 29, 4005 (1990).

6) D. D. Perrin and W. L. F. Armargeo, Purification of Laboratory Chemicals, 3rd. ed., Pergamon, New York (1988). 
7) Kagaku Binran, Kiso-hen, Chemical Society of Japan, Maruzen, Tokyo, p. II-597 (1984).

8) A. T. Hubbard, CRC Crit. Rev. Anal. Chem., 2, 201 (1973). 